\title{
Peranan Kearifan Lokal Sistem Sasi Dalam Pengelolaan Sumber Daya Laut Indonesia
}

\author{
Nurfani Indah Putri ${ }^{*}$, Ni Luh Chandrika ${ }^{1}$, Gia Laras Pangestu ${ }^{1}$, Ade Suryanda ${ }^{1}$ \\ ${ }^{1}$ Universitas Negeri Jakarta, Jl. Rawamangun Muka, RT.11/RW.14, Rawamangun, Pulo Gadung, Kota \\ Jakarta Timur, Daerah Khusus Ibukota Jakarta 13220
}

\section{Kata Kunci:}

Kearifan Lokal

Sasi

Sumber Daya Alam

\begin{abstract}
Abstrak
Indonesia sebagai pemilik keanekagaraman hayati terbesar memiliki pula berbagai kearifan lokal yang didalamnya tersimpan jutaan makna. Sasi merupakan salah satu bentuk kearifan lokal yang berasal dari Maluku. Bentuk kearifan lokal ini yaitu upaya untuk melestarikan sumber daya alam darat maupun laut serta dapat membantu upaya konservasi. Oleh karena itu, penelitian ini bertujuan untuk mengetahui peranan sasi sebagai sistem dalam pengelolaan sumber daya laut berbasis kearifan lokal di wilayah pesisir Indonesia. Metode penelitian yang digunakan dalam penelitian ini ialah studi literatur, yaitu membaca, mempelajari, mengkaji, serta menganalisis terkait dengan literatur yang berhubungan dengan peranan sasi sebagai kearifan lokal dalam pengelolaan sumber daya laut Indonesia. Hasil penelitian menunjukkan bahwa Sasi sebagai kearifan lokal masyarakat adat Maluku adalah modal dan model pengelolaan serta perlindungan lingkungan di tingkat regional, khususnya Maluku dan nasional, di mana penggunaan sumber daya alam harus harmonis dan seimbang fungsi lingkungannya.
\end{abstract}

Keywords:

Local Wisdom

Sasi

Natural Resources

\footnotetext{
*Penulis koresponden: NurfaniIndahPutri_1304617069@mhs.unj.ac.id
} 


\section{PENDAHULUAN}

Wilayah laut Indonesia sangat luas dan mendominasi total luas dari teritorial Indonesia, wilayah laut Indonesia memiliki luas sebesar 7.7 juta $\mathrm{km}^{2}$ dan memiliki panjang garis pantai $104.000 \mathrm{~km}^{2}$. Karena memiliki wilayah laut yang luas, sehingga Indonesia merupakan negara yang kaya dan memiliki keanekaragaman hayati dan non hayati terbesar di dunia (Data pusat statistik KKP, 2011). Indonesia juga disebut sebagai negara yang memiliki Mega-biodiversity terbesar di dunia dan salah satu negara bahari terbesar di dunia, hal itu didukung karena luas wilayah yang besar dan juga kondisi geografis serta struktur dan tipologi ekosistem yang didominasi lautan (Dahuri 2003, 5).

Indonesia sebagai pemilik keanekaragaman hayati terbesar di dunia harus menghadapi tantangan yang berat dalam eksploitasi sumber daya yang berlebihan terhadap sumber daya laut dan pesisir, dan eksploitasi yang tidak ramah lingkungan dapat menyebabkan penurunan hasil laut, yang menyebabkan kerugian yang berdampak kedepan pada generasi penerus. Untuk itu perlu sebuah cara agar eksploitasi sumber daya laut mengedepankan aspek keberlanjutan, dengan cara membentuk kawasan konservasi, dalam kawasan tersebut nantinya dibuat peraturan untuk melindungi ekosistem didalamnya agar tetap lestari (Setiyono 2016).

Pemerintah pusat memiliki wewenang dalam menetapkan kawasan konservasi, yaitu meliputi taman nasional, taman hutan, serta taman wisata alam yang semuanya itu diatur dalam Undang-Undang Nomer 5 Tahun 1990 (Damanik, et al. 2006). Kemudian dalam pengelolaan sumber daya merupakan wewenang pemerintah pusat yang diatur dalam UUD 1945 Pasal 33 Ayat 3 dimana air, bawah tanah, dan sumber daya alam yang terkandung didalamnya di kelola oleh negara yang bertujuan untuk kemakmuran rakyat. Karena itu, pemerintah menetapkan instrumen kebijakan suatu wilayah sebagai kawasan konservasi, tetapi penetapan kawasan konservasi sering mengabdikan hak-hak masyarakat untuk akses dan mengontrol sumber daya laut (Satria 2009) salah satu contohnya adalah penetapan wilayah konservasi perairan dalam Peraturan Daerah Kabupaten Raja Ampat No. 27 Tahun 2008 yang mengalami pro dan kontra. Eksploitasi sumber daya laut mengedepankan aspek keberlanjutan, dengan cara membentuk kawasan konservasi, dalam kawasan tersebut nantinya dibuat peraturan untuk melindungi ekosistem didalamnya agar tetap lestari.

Eksploitasi sumber daya laut yang mengedepankan keberlanjutan melalui kawasan konservasi dapat dimulai dari adanya otonomi daerah dalam pengelolaan sumber daya laut dan perikanan dikarenakan terdapat ruang bagi masyarakat lokal dalam berpartisipasi mengelola sumber daya. Dalam pasal 6 UndangUndang Nomor 31 Tahun 2004, menyatakan bahwa pengelolaan perikanan untuk kepentingan penangkapan ikan dan budidaya ikan harus memiliki pertimbangan hukum adat atau dengan kata lain kearifan lokal serta peran masyarakat (Satria 2009).

Hasani (2014) mengatakan bahwa wilayah konservasi dimana mengedepankan masyarakat atau biasa disebut CommunityBased Management yang disingkat sebagai CBM merupakan strategi dalam pembangunan yang berpusat pada manusia, pada sistem ini masyarakat sendiri diberikan tanggungjawab dalam pengelolaan sumber daya yang dimiliki, dimana masyarakat dapat mendefinisikan kebutuhan, tujuan, dan aspirasinya dan membuat keputusan untuk kesejahteraannya.

Kearifan lokal adalah daya tahan dan daya tumbuh yang kemudian dimanifestasikan melalui pandangan hidup dan berbagai strategi kehidupan yang dilakukan oleh masyarakat lokal untuk menjawab berbagai masalah dalam pemenuhan kebutuhan, dan memelihara kebudayaan. Kearifan lokal sasi merupakan jawaban untuk bertahan dan menumbuhkan kebudayaan serta sebagai sistem dalam menjaga kelestarian lingkungan (Kusumadinata 2015)

Sasi merupakan salah satu upaya dalam mengelola wilayah konservasi yang berbasis masyarakat di Indonesia dan mengelola sumber daya pesisir laut. Sasi adalah upaya unuk melestarikan sumber daya alam darat maupun laut oleh masyarakat Malaku kemudian menyebar kebeberapa daerah di Papua Barat (Ummanah, 2013). Sasi merupakan sistem dalam mengatur waktu atau periode kapan suatu sumber daya dapat dipanen, dan merupakan kearifan lokal yang dapat membantu upaya 
konservasi yang dikategorikan oleh IUCN dalam kriteria VI (Persada, Nadia, P. R; Mangunjaya, F.M; Tobing 2018). Maka dari itu penelitian ini bertujuan untuk mengetahui peranan sasi sebagai sistem dalam pengelolaan sumber daya laut berbasis kearifan lokal di wilayah pesisir Indonesia.

\section{METODE PENELITIAN}

Metode yang digunakan dalam penyusunan artikel ini adalah metode studi literatur dengan membaca, mempelajari, mengkaji, dan menganalisis literatur-literatur yang berhubungan dengan dengan kearifan lokal, sasi, dan sumber daya laut.

\section{HASIL DAN PEMBAHASAN}

Zona pesisir Indonesia kaya akan ekosistem laut tropis seperti pantai estuarial, bakau, terumbu karang, lamun, hamparan alga dan ekosistem pulau kecil yang merupakan rumah dari berbagai varietas komunitas yang hidup dengan berbagai jenis asosiasi serta kekayaan keanekaragaman spesies. Habitat pesisir lainnya seperti pantai berpasir dan berlumpur, flat pasir atau lumpur, meskipun menampung keanekaragaman hayati yang relatif lebih buruk tetapi secara ilmiah menarik. Masing-masing ekosistem laut ini, dengan habitatnya yang terkait, mendukung kekayaan keanekaragaman hayati laut yang tidak dieksplorasi dengan baik dan sangat buruk didokumentasikan. Data organisme laut dengan yang disajikan menunjukkan bahwa informasi tentang taksa laut, terutama hewan, sangat miskin (Hutomo 2015, 34).

Sumber daya alam terutama sumber daya laut yang kita miliki merupakan sebuah aset yang sangat penting bagi Indonesia, kekayaan alam tersebut terkadang dieksploitasi secara bebas dimana masyarakat diperbolehkan mengambil apa saja yang terdapat dalam laut untuk memenuhi kebutuhan, tetapi jika pengambilan sumber daya laut ini dilakukan eksploitasi secara besar-besaran akan menimbulkan kerusakan bagi ekosistem, dan kegiatan tersebut akan menimbulkan kepunahan. Maka dari itu diperlukan pengelolaan dengan bijak sumber daya, agar keseimbangan ekosistem terus terjaga (Persada,
Nadia, P. R; Mangunjaya, F.M; Tobing 2018, 6871).

Eksploitasi secara besar besaran oleh masyarakat memerlukan solusi dan gagasan dalam pengelolaan sumber daya laut, dimana diperlukan pembangunan berkelanjutan yang sangat perlu diterapkan agar dapat memenuhi sumber daya secara optimal dan berkesinambungan terhadap fungi ekonomis dan ekologis. Pengelolaan sumber daya yang berkelanjutan diharapkan dapat menyebabkan lingkungan tetap lestari dari generasi ke generasi (Karepesina, et al. 2013).

Pengelolaan sumber daya laut sendiri adalah proses yang didorong oleh politik dan budaya, dibentuk oleh mata pencaharian dan persepsi manusia, dimana gagasan tentang ruang dan tempat membentuk kebijakan dan pengambilan keputusan secara mendasar. Subbidang yang muncul dalam geografi secara kritis mengeksplorasi aspek-aspek geografis pengelolaan sumber daya laut (Levine 2015, 5659).

Keberadaan aturan sasi membantu masyarakat dalam mengelola dan menjaga sumber daya disekitarnya yang dapat dimanfaatkan secara berkelanjutan, dan sasi memiliki nilai budaya dalam pengelolaan dan pemanfaatan sumber daya secara berkelanjutan oleh masyarakat dan berdasarkan pengetahuan lokal yang diturunkan dari generasi ke generasi, serta bertujuan agar ketersediaan sumber daya dapat terus dimanfaatkan oleh generasi selanjutnya (Elfemi 2013).

\section{Definisi Sasi}

Sasi berasal dari kata "sanksi" yang artinya larangan. Larangan yang terkandung dalam sasi adalah larangan dalam pemanfaatan sumber daya alam di darat maupun di laut dalam jangka waktu tertentu yang bertujuan untuk pemenuhan kepentingan ekonomi masyarakat. Selain itu sasi dapat didefinisikan sebagai larangan dalam mengambil ataupun merusak sumber daya alam dalam jangka waktu tertentu yang bertujuan untuk kelestaraian sumber daya alam (Kusumadinata 2015).

Sasi memiliki aturan dan tata cara pelaksanaan, dan pemanfaatan serta pemeliharaan dan pengawasan dalam menjaga keseimbangan lingkungan dan sumber daya alam agar keduanya dapat dimanfaatkan terus sampai kegenerasi berikutnya. Sasi merupakan hukum adat yang mengajarkan bagaimana manusia mempertahankan kelangsungan hidup 
dan tidak menggunakan sumber daya alam secara berlebihan untuk menciptakan keseimbangan alam. Sasi memiliki norma dan aturan dalam cara, kebiasaan, tata kelakuan yang didalamnya terdapat unsur etika dan norma (Sofyaun 2012).

\section{Persebaran Sistem Sasi di Indonesia}

Adat istiadat-Sasi adalah asal budaya Maluku yang diwariskan oleh nenek moyang Maluku sejak berabad-abad lalu. Seiring perkembangan zaman, Sasi masih dilestarikan oleh rakyat di negeri raja-raja ini. Awalnya, kebiasaan Sasi dilakukan oleh raja-raja Maluku di era pra-kemerdekaan. (Priyo 2019, 203). Sistem sasi ini meluas sampai ke wilayah papua barat (Patriana, et al. 2016). Menurut astika (2016) sasi yang tersebar di wilayah maluku terdiri dari wilayah Halmaera, Ternate, Buru, Seram, Kepulauan Lease, Watubela, Banda, dan beberapa kepulauan lainnya seperti kepulauan Barat Daya, dan kepulauan Tenggara. Selain itu Sasi memiliki nama lain pada wilayah Kei Besar dan wilayah Kei Kecil, pada wilayah Kei Besar nama lain sasi adalah $Y o t$ sedangkan di wilayah Kei Kecil nama lain sasi adalah Yutut. (Damardjati dan Kusrini 2015).

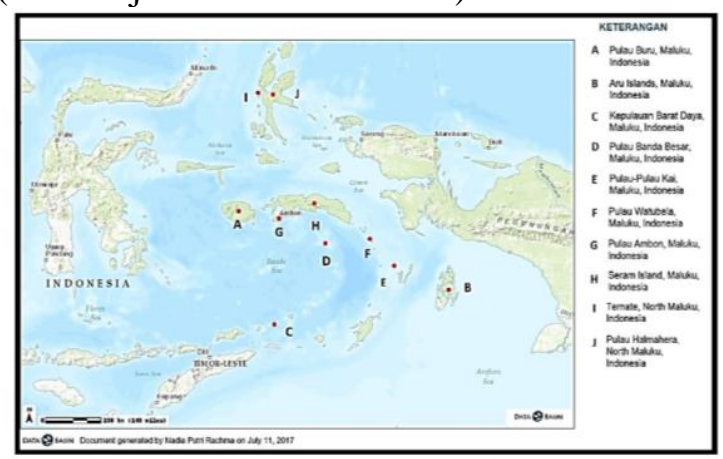

Gambar 1. Peta wilayah kepulauan Maluku yang mengaplikasikan sistem sasi

Sumber gambar: Persada, Nadia, P. R; Mangunjaya, F.M; Tobing 2018

Persebaran sasi selain tersebar di Kepulauan Maluku, sistem sasi ini tersebar hingga ke wilayah Papua Barat yang meluputi beberapa wilayah seperti Sorong, Manokwari, Nabire, Biak, Yapan, Waropen, Sami, Nufor, Kaimana, dan Fakfak, serta kepulauan Raja Ampat (Astika 2016).

\section{Lembaga yang Berperan dalam Pelaksanaan Sistem Sasi}

Dalam pelaksanaan sasi diperlukan berbagai pihak dalam mengelola sistem sasi ini.
Terdapat Lembaga adat yang memiliki wewenang dalam pelaksanaan sistem sasi ini, lembaga adat tersebut dapat juga memiliki struktur dan fungsinya masing-masing ketika sistem sasi ini dilaksanakan. Struktur Lembaga adat dalam pelaksanaan sistem sasi ini dapat kita lihat pada gambar di bawah ini.

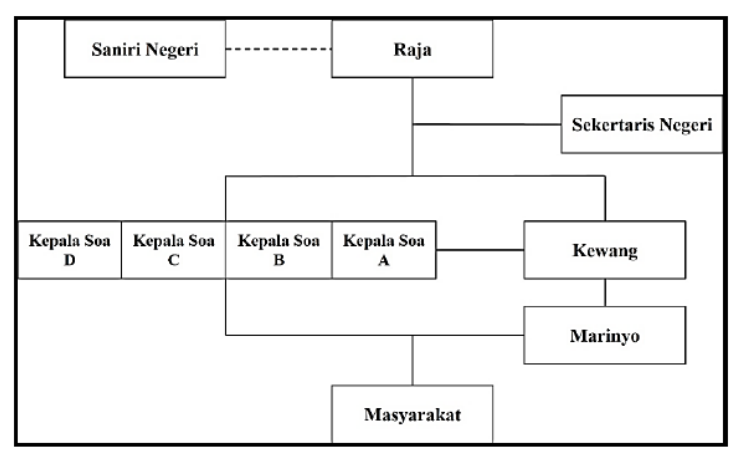

Gambar 2. Struktur Lembaga adat yang berperan dalam sistem sasi

Sumber gambar: Persada, Nadia, $P . \quad R$; Mangunjaya, F.M; Tobing 2018

Dimulai dari Saniri Negeri merupakan Lembaga adat yang memiliki wewenang dalam menetapkan suatu keputusan, dan saniri negeri ini memiliki fungsi dalam melakukan pengawasan atau Lembaga legislatif terhadap keputusan-keputusan yang akan dibuat (Etlegar 2013). Kemudian saniri negeri membantu raja dalam memberikan keputusan. Raja berperan sebagai kepala pemerintahan negeri atau pimpinan lemabaga adat, dan raja memiliki wewenang dalam menentukan pelaksanaan buka dan tutup sasi. Selain dibantu saniri, raja juga dibantu oleh sekretaris negeri yang memiliki fungsi dalam administrasi pemerintahan dan juga sekretaris negeri memiliki peran dalam pelayanan administrasi kepada masyarakat (Etlegar 2013).

Terdapat Kepala Soa merupakan pemimpin atau perwakilan dari suatu soa, yag memiliki fungsi untuk menampung serta menyalurkan aspirasi dari suatu soa yang dipimpinnya. Kewang adalah perwakilan dari masing masing soa dan memiliki fungsi sebagai polisi negeri karena kewang memiliki tugas serta wewenang dalam menjaga dan mengawasi lingkungan atau wilayah sasi, dan mencegah masyarakat melakukan pelanggaran dan merusak sumber daya alam. Keputusankeputusan tentang pelaksanaan sasi yang sudah dirapatkan oleh raja bersama Lembaga sasi lainnya disampaikan oleh Marinyo, Marinyo 
memiliki tugas dan wewenang dalam menyampaikan berita dari raja ataupun ketua adat dan Lembaga adat lainnya untuk disampaikan kepada masyarakat, informasi yang disampaikan baik secara lisan maupun tulisan serta mengantarkan surat panggilan kepada masyarakat yang melanggar aturan (Etlegar 2013).

\section{Peranan Sasi dalam Pengelolaan Pesisir dan Sumber Daya Laut}

Sasi adalah untuk perlindungan sumber daya alam dari produk lola, teripang atau kopra, di darat atau di laut, jika sasi tidak diinstal maka lola tidak dapat diambil, jadi sampai umur satu tahun sampai dua tahun panen baru bisa diambil. Sasi yang berlaku dimasyarakat berguna untuk menjaga kualitas dan menjaga populasi sumber daya hayati. Sasi juga bisa diartikan sebagai tradisi yang dilakukan oleh masyarakat dengan tujuan utama menjaga keberlanjutan sumber daya. Jika Sasi telah diterapkan oleh masyarakat maka dampaknya adalah masyarakat tidak akan berani untuk melanggar peraturan tersebut, sehingga sistem ini sangat tepat digunakan sebagai sarana mengelola sumber daya alam baik di darat maupun di laut (Priyo 2019, 203).

Dalam pelaksanaan sasi dibuat berdasarkan pengetahuan masyarakat tentang waktu atau periode tertentu untuk mengetahui kapan suatu sumber daya dapat dipanen sehingga siklus hidup suatu organisme tidak terganggu (Damardjati and Kusrini 2015). Dalam pelaksanaan sasi terdapat istilah Buka Sasi dan Tutup Sasi. Buka sasi adalah waktu dimana masyarakat diperbolehkan untuk memanen atau masyarakat diperbolehkan untuk mengambil sumber daya yang sedang dilakukan sasi, dan tutup sasi merupakan waktu dimana masyarakat tidak boleh mengambil sumber daya yang ada (Etlegar 2013).

Sasi laut akan dibuka berdasarkan keputusan Lembaga adat dan disampaikan oleh Marinyo kepada masyarakat, dan penyampaian pembukaan sasi ini disampaikan cara berteriak keliling desa. Waktu sasi dibuka memiki beberapa alasan seperti permintaan pasar untuk pemenuhan ekonomi, dan kebutuhan konsumsi masyarakat serta keperluan sosial lainnya seperti pembangunan tempat ibadah perbaikan tempat ibadah dan adanya perayaan hari besar keagamaan (Sofyaun, 2012).
Batas wilayah dalam pelaksanaan sasi biasanya dilakukan dengan cara menarik garis lurus kearah laut dari pantai hingga batas tepi terumbu karang (Solihin 2010). Batas tepi atau biasa disebut dengan batas tubir yang terdiri dari ekosistem terumbu karang, dimana ekosistem ini memiliki fungsi dalam perkembangbiakan biota laut dan tempat mencarai makan biota laut diantara terumbu karang, maka dari itu batas ini dibedakan agar masyarakat mengetahui mana batas yang boleh dimanfaatkan dan mana wilayah yang dilarang. Batas sasi biasanya berupa tongkat kayu yang dililit oleh daun kelapa muda atau biasa disebut dengan janur dan ditancapkan pada lokasi wilayah sasi, lokasi yang di beri tanda sasi, menandakan dimana masyarakat tidak boleh mengambil bahkan melakukan aktivitas apapun yang dapat mengganggu biota didalamnya.

Salah satu penerapan wilayah sasi yang dilakukan Distrik Misool Barat Raja Empat sumber daya yang dilindungi sasi dibatasi dengan menggunakan tanda batas alam seperti batas antara kampung ke kampung dan antara pulau kepulau dan untuk membuat masyarakat tahu bahwa daerah tersebut merupakan wilayah sasi maka akan digunakan kayu-kayu, pelampung ataupun papan yang bertuliskan sasi (Lestari and Satria 2015).

Sumber daya yang dilindungi sasi diberlakukan hanya unuk jenis-jenis biota laut tertentu, umumnya biota yang diberlakukan pada penerapan sistem sasi merupaka biota laut yang memiliki nilai ekonomis yang tinggi dan merupakan target konsumsi pasar dan masyarakat lokal. Biota laut yang biasa disasikan seerti Ikan Lompa Thryssa baelama, Tripang Holothuroidea spp dan siput Lola Trochus niloticus. Ketiga biota tersebut merupakan biaota laut yang pada umumnya dilakukan sistem sasi, alasannya dikarenakan ketiga biota ini memiliki nilai ekonomi yang tinggi, tetapi terkadang sistem sasi juga berlaku untuk melindungi udang atau lobster dan rumput laut.

Ikan Lompa termasuk dalam family Engaraulidae dimana ikan ini hidup dalam perairan laut tropis dan juga dapat ditemukan dalam perairan payau, ikan lompa memiliki ukuran tubuh 0-5 meter dan hidup disekitar terumbu karang (Whitehead 1988). Ikan lompa dapat ditemukan dalam beberapa kepualauan Indonesia seperti pulau Ambon, Pulau Seram dan Pulau Haruku (Mainnassy, et al. 2011). Ikan lompa secara ekologi mempunyai peranan 
penting dalam rantai makanan dimana merupakan sumber makanan bagi ikan-ikan lainnya. Pembukaan sasi pada ikan lompa dimulai selama 5-7 bulan (Kareoesina, et al. 2013). Tutup sasi dilakuakan jika waktu buka sasi telah selesai, maka tanda wialyah sasi akan kembali dipasang.

Tripang merupakan salah satu biota laut yang dilindungi oleh sistem sasi. Tripang banyak ditemukan pada substrat yang berpasir, maupun berlumpur dan substrat batauan atau karang, tripang biasa ditemukan disekitar lamun atau alga yang bertujuan agar terlindung dari adanya hempasan ombak. Di Kepulauan Maluku, tripang merupakan salah satu biota laut yang memiliki nilai ekonomi yang tinggi dan tersebar di hampir seluruh wilayah Kepulauan Maluku seperti Pulau Buntal, Pulau Sapura, Kepulauan Kei , Kepulauan Seram, dll. Pelakasanaan pembukaan sasi pada tripang seperti desa Proto, Pulau Sapura, kabupaten Maluku Tengah, sasi dibuka pada bulan oktober dan berlangsung selama dua minggu, serta pengambilan tripang dilakukan pada malam hari, dikarenakan pada malam hari tripang akan muncul kepermukaan dan memudahkan dalam proses panen (Lawerissa 2009). Jika waktu pembukaan sasi telah selesai maka sasi akan ditutup kembali dengan isyarat penutupan sasi, seperti tanda berupa janur kuning.

Lola merupakan biota laut yang termasuk dalam perlindungan sistem sasi, apalagi menurut pemerintah lola merupakan satwa yang dilindungi berdasarkan Peraturan Pemerintah Nomer 7 Tahun 1999. Ukuran lola yang boleh diambil sebesar $8 \mathrm{~cm}$, jika lola lebih kecil dari ukuran tersebut maka Lola tidak dapat diambil (Tuhumury and Frederik 2011). Sasi lola dibuka setiap 2-3 tahun dan dilakukan sebanyak 2-3 kali (Adhuri 2004). Penutupan waktu sasi juga sama seperti yang dilakukan pada penutupan waktu sasi biota laut tripang dan ikan lompa.

Jika masyarakat melakukan pelanggaran pada peraturan sasi yang telah ditetapkan maka akan diberikan sanksi. Pelanggaran sasi memiliki beberapa sanksi. Pelanggaran sasi umum (disebut hawear), yaitu sasi dengan tanda janur woven, akan dikenakan denda berat, sedang atau ringan. Sanksi akan ditentukan dan dipertimbangkan dalam Dewan Adat setempat (Seniri). Pertama adalah sanksi sosial dimana akan terjadi perang jika ada pelanggaran sasi oleh pihak lain. Yang kedua adalah sanksi para leluhur. Sanksi kedua ini kerap ditakuti sehingga mereka tidak akan berani menghancurkan sasi meskipun tidak ada yang melihatnya. Namun disana biasanya yang menjadi patokan dasar dalam penentuan denda hukuman ini, yaitu: 1) Lela (meriam kuno) atau 3 tahil emas; 2) menanggung biaya litigasi yang jumlahnya ditentukan oleh pertemuan Dewan Adat; atau 3) Bentuk hukuman lain sesuai dengan pertimbangan pertemuan Bea Cukai Dewan. Hukum dan aturan tentang sasi adalah kearifan lokal dari orang Maluku Tenggara. Kebiasaan dan nilai-nilai yang ada dalam masyarakat merupakan dasar aturan perilaku anggota masyarakat. Hal ini dapat merugikan masyarakat jika kekayaan adat dan budaya di kepulauan Indonesia tidak dipelihara dan dikembangkan. Karena itu, membutuhkan upaya untuk mengekstraksi nilai-nilai kearifan lokal (Basyari 2014, 47-56).

\section{PENUTUP}

Melihat bentuk manajemen dan lingkungan perlindungan masyarakat adat Maluku, bisa dikatakan begitu tujuan utama sasi di Maluku adalah perwujudan dari kesadaran dan kearifan lokal masyarakat adat Maluku di Indonesia seperti pengelolaan, perlindungan dan pelestarian lingkungan sebagai modal dasar. Dengan keberadaan sasi, masyarakat asli tidak akan mengelola sumber daya alam mereka dengan sia-sia, sehingga sumber daya alam yang ada dapat efisien dan berkelanjutan untuk manfaat dan kesejahteraan masyarakat. Keberadaan rakyat asli sebagai bagian dari negara kesatuan republik Indonesia ini diakui oleh hak adat dan sistem hukumnya, termasuk sumber daya alam di wilayahnya. Karena itu, masyarakat adat perlu diberi kesempatan untuk mengelola dan memanfaatkan sumber daya alam di wilayah mereka sesuai dengan kearifan lokal mereka. Sasi sebagai kearifan lokal masyarakat adat Maluku adalah modal dan model pengelolaan serta perlindungan lingkungan di tingkat regional, khususnya Maluku dan nasional, di mana penggunaan sumber daya alam harus harmonis dan seimbang fungsi lingkungannya. 


\section{DAFTAR PUSTAKA}

Asrul, Rindarjono MG, Sarwono. 2017. Eksistensi sasi dalam pengelolaan lingkungan hidup dan peran serta masyarakat di negeri Haruku kabupaten Maluku Tengah provinsi Maluku tahun 2013. Jurnal EcoGeo Vol. 3 (1): 69-81.

Adhuri DS. 2004. How can traditional marine resource management support a responsible fishery? Lessons learned from Maluku. Proceeding The International Institute of Fisheries Economics \& Trade (IIFET)..

Basyari. 2014. Nilai-Nilai Kearifan Lokal (Local Wisdom) Tradisi Memitu Pada Masyarakat Cirebon. Edunomic Volume 2 No. 1 Tahun, pp. 47-56

Boli P, Yulianda F, Damar A et al. 2014. Benefits of sasi for conservation of marine resources in Raja Ampat, Papua. Jurnal Manajemen Hutan Tropika Vol. 2010 (2): 131-139.

Dahuri, Rokhmin. 2003. "Paradigma Baru Pembangunan Indonesia Berbasis Kelautan." Orasi Ilmiah Fakultas Perikanan Dan Ilmu Kelautan, 1-65.

Damanik R., A, Satria. dan B. Prasetiamartati. 2006. Menuju konservasi laut yang pro rakyat dan pro lingkungan. Wahana Lingkungan Hidup Indonesia (WALHI). Jakarta.

Damardjati KM, Kusrini T. 2015. Pelestarian lingkungan berbasis kearifan lokal. Pusat Penelitian Kebijakan Pendidikan dan Kebudayaan Kementerian Pendidikan dan Kebudayaan.

Elfemi N. 2013. Sasi, kearifan lokal dalam pengelolaan sumber daya laut (Kasus; Masyarakat suku Tanimbar di desa Adaut, kecamatan Selaru, kabupaten Maluku Tenggara Barat). Jurnal Pelangi Vol 6 (1) : 23-30.

Etlegar D. 2013. Peran lembaga adat sasi dalam pengelolaan sumberdaya dusun di negeri Allang kecamatan Leihitu Barat, kabupaten Maluku Tengah. Skripsi. Departemen Manajemen Hutan. Institut Pertanian Bogor. Bogor.

Fridayanthie, E. wida. 2016. IOSR Journal of Economics and Finance, 3(1), 56. https://doi.org/https://doi.org/10.3929/e thz-b-000238666H

Hasani, Q. 2014. Konservasi Sumberdaya Perikanan Berbasis Masyarakat, Implementasi Nilai

Luhur Budaya Indonesia Dalam Pengelolaan Sumberdaya Alam. Jurnal Ilmu Perikanan

dan Sumberdaya Perairan pg 10. Universitas Lampung, Bandar Lampung.

Hutomo, Malikusworo \& Kasim, Mohammad. 2005. Indonesian Marine and Coastal biodiversity: Present status. Indian Journal of Marine Sciences pg 34.

Karepesina SS, Susilo E, Indrayani E. 2013. Eksistensi hukum adat dalam melindungi pelestarian sasi ikan lompa di desa Haruku Kabupaten Maluku Tengah. Jurnal ECSOFiM Vol. 1 (1) : 25-41.

Knight J. 1992. Institutions and Social Conflict. New York: Cambridge University Press

Kusumadinata, A. 2015. Peran Komunikasi Dalam Menjaga Kearifan Lokal ( Studi Kasus Sasi Di Desa Ohoider Tawun , Kabupaten Maluku Tenggara ). Jurnal Sosial Humaniora, 6(April), 23-32.

Latuconsina H. 2009. Eksistensi sasi laut dalam pengelolaan perikanan berkelanjutan berbasis komunitas lokal di Maluku. Jurnal Manajemen Sumberdaya Perairan TRITON Vol. 5 (1): 63-71.

Lestari, E., \& Satria, A. 2015. Peranan Sistem Sasi Dalam Menunjang Pengelolaan Berkelanjutan Pada Kawasan Konservasi Perairan Daerah Raja Ampat. Buletin Ilmiah Marina Sosial Ekonomi Kelautan Dan Perikanan, 1(2),

67.https://doi.org/10.15578/marina.v1i 2.2073

Levine, dkk. 2015. Marine resource management: Culture, livelihoods, and governance. Volume 59, May 2015, Pages 56-59. https://doi.org/10.1016/j.apgeog.2015. 01.016.

Lewerissa YA. 2009. Pengelolaan teripang berbasis sasi di negeri Porto dan desa 
Warialau provinsi Maluku. Thesis. Sekolah Pasca Sarjana Institut Pertanian Bogor.

Mantjoro E. 1996. Traditional Management of Communal Property Resources: the Practice of the Sasi System. Ocean \& Coastal Management, Vol. 32/1, pp. 1737

Negeri Tihulale, "tihulale,".2017. Available: http://www.tihulale.com/2017/03/sasi

tradisi menjaga-sumber-

daya.html.Dahuri, Rokhmin. 2003.

"Paradigma Baru Pembangunan Indonesia

Berbasis Kelautan." Orasi Ilmiah Fakultas

Perikanan Dan Ilmu Kelautan, 1-65.

Lestari, Elva, and Arif Satria. 2015. "Peranan Sistem Sasi Dalam Menunjang Pengelolaan Berkelanjutan Pada Kawasan Konservasi Perairan Daerah Raja Ampat." Buletin Ilmiah Marina Sosial Ekonomi Kelautan Dan Perikanan 1 (2): 67. https://doi.org/10.15578/marina.v1i2.207 3.

Persada, Nadia, P. R; Mangunjaya, F.M; Tobing, I. SL. 2018. "Sasi Sebagai Budaya Konservasi Sumber Daya Alam Di Kepulauan Maluku.” Ilmu Dan Budaya 41 (59): 6869-6900.

Satria, A. 2007. Sawen Instituion, local knowledge and myth in fiheries management in North Lombok, Indonesia.Fishers' knowledge in fisheries science and management. Paris: UNESCO

Satria A., A, Umbari., A, Fauzi., A, Purbayanto., E, Sutarto., I, Muchsin., I, Muflikhati., M, Karim., S, Saad., W, Oktariza. dan Z, Imran. 2002. Мепијu desentralisasi kelautan. Jakarta: Pusat kajian Agraria IPB dengan PT Pustaka Cidesindo

Setiyono, Edi. 2016. Pengelolaan Sumberdaya Pesisir Berbasis Masyarakat (Pbm) Melalui Awig-Awig Di Lombok Timur Dan Sasi Di Maluku Tengah. Sabda: Jurnal Kajian Kebudayaan 11 (1): 46. https://doi.org/10.14710/sabda.v11i1.1 $\underline{3229}$.

Sofyaun A. 2012. Analisis kelembagaan sasi dalam pengelolaan perikanan tangkap di kecamatan Seram Timur. Skripsi.
Departemen Pemanfaatan Sumberdaya Perikanan. Institut Pertanian Bogor.

Solihin A. 2011. Sasi teripang: Upaya konservasi dalam membangun desa pesisir. Prosiding Seminar Nasional Pengembangan Pulau-pulau Kecil. $h$. 33-40. ISBN: 978-602-98439-2-7.

Tuhumury, Frederik S. 2011. Analisis aspek bioekologi, sosekbud, hukum dan kelembagaan dalam pengelolaan sumberdaya siput Lola (Trochus niloticus, Linn) di pesisir pulau Saparua, kecamatan Saparua, kabupaten Maluku Tengah provinsi Maluku. Thesis. Universitas Diponergoro. Semarang.

Ummanah. 2013. Sasi laut komunitas nelayan di Maluku Tenggara, provinsi Maluku. Jurnal Ilmiah Pariwisata Vol. 18 (3). 